\title{
1820: RUPTURA ENTRE LA JERARQUIA ECLESIÁSTICA Y EL ESTADO CONSTITUCIONAL
}

\section{0: BREAK BETWEEN CHURCH HIERARCHY AND CONSTITUTIONAL STATE}

\author{
Emilio La Parra López \\ Universidad de Alicante
}

\begin{abstract}
SUMARIO: I. INTRODUCCIÓN.- II. DISTANCIAMIENTO ENTRE LOS DOS PODERES.- III. LA OFENSIVA POLÍTICA DEL NUNCIO GIUSTINIANI.- IV. PROTESTAS DEL EPISCOPADO.- V. CONCLUSIÓN
\end{abstract}

Resumen: En 1820 el clero español acató la orden de la autoridad civil de jurar la Constitución. Este acto fue en realidad una formalidad, pues la jerarquía eclesiástica rechazó de plano la política reformista del régimen constitucional y acusó al liberalismo de atentar contra la Iglesia y la religión. El enfrentamiento entre el poder civil y el eclesiástico se agravó con el tiempo, hasta llegar a la ruptura. El núcleo de la desavenencia no fue la religión, ni la propia Iglesia, que todos respetaron, sino la disputa por el poder entre ambas autoridades. Este texto pretende ofrecer una explicación de esa ruptura, poniendo el foco de atención en las actuaciones del nuncio de la Santa Sede y de algunos obispos españoles.

\begin{abstract}
In 1820 the Spanish clergy complied with the order of the civil authority to swear the Constitution. This act was actually a formality, since the ecclesiastical hierarchy rejected outright the reformist policy of the constitutional regime and accused liberalism of attacking the Church and religion. The confrontation between the civil power and the ecclesiastical one got worse with time, until it reached the rupture. The core of the disagreement was not religion, nor the Church itself, which everyone respected, but the dispute for power between the two authorities. This text tries to explain this rupture, putting the focus of attention on the actions of the nuncio to the Holy See and some Spanish bishops.
\end{abstract}

Palabras clave: política liberal, episcopado, Giustiniani, Iglesia católica.

Key Words: Liberal Policy, Episcopacy, Giustiniani, Catholic Church

\section{INTRODUCCIÓN}

Tras anunciar Fernando VII, el 7 de marzo, su disposición a jurar la Constitución, la jerarquía de la Iglesia católica española no se manifestó frontalmente en contra de un texto que, sin embargo, años antes habia rechazado. La mayoria, ha escrito Manuel Revuelta, se mantuvo "a la expectativa" 
ante la implantación por segunda vez del constitucionalismo, ${ }^{1}$ pero esta actitud duró muy poco, pues salvo casos contados, el alto clero no tardó en reaccionar activamente ante la política del nuevo régimen, hasta convertirse en uno de los focos de oposición más férreos. Unos han atribuido esta mudanza a la política eclesiástica de los liberales, que califican de errónea, o al menos de apresurada. Otros han resaltado la inveterada hostilidad de la mayor parte del clero al programa de reformas eclesiásticas iniciado por la Ilustración avanzada y continuado en lo sustancial por el primer liberalismo en los años de las Cortes de Cádiz y en el Trienio Liberal. En cualquier caso, llegados a este último periodo, se hizo patente la ruptura entre el poder civil y el eclesiástico. Siempre habían existido conflictos entre ambas potestades, pero no habían pasado de ser disputas esporádicas, las más de las veces de carácter personal, cuya resolución, fuera o no asumida por una de las partes, no alteró el statu quo. ${ }^{2}$ En el Trienio se dio un paso adelante en este punto.

Me parece cuestión secundaria dilucidar a quién correspondió la responsabilidad de la ruptura, si al cuerpo eclesiástico o a las nuevas autoridades politicas y grupos liberales más o menos definidos, tales como las sociedades patrióticas. No resultaría dificil aducir testimonios en favor de una $u$ otra posibilidad, pero me temo que ello nos conduciría a un debate estéril. ${ }^{3}$

Para responder a la pregunta: ¿cómo y por qué se llegó a la ruptura?, me parece que 1820 es la fecha clave, y por esta razón, aquí me centraré en ella. En ese año se tomaron las decisiones más importantes en materia eclesiástica del Trienio (la excepción fue el decreto sobre la reducción del diezmo a la mitad, de 29 de junio de 1821). Además, el debate político no se vio condicionado por el movimiento armado realista como lo sería en los años siguientes, especialmente en 1822 y 1823, en el que tanta parte cupo a los eclesiásticos. No cabe olvidar, por otra parte, que en 1820 algunos -en particular los clérigos tildados de liberales- todavía mantenian la esperanza de llegar a cierto entendimiento entre la Iglesia católica y el constitucionalismo liberal.

\footnotetext{
${ }^{1}$ Manuel Revuelta González, "La Iglesia española ante la crisis del Antiguo Régimen (1808-33)", en Ricardo Garcia Villoslada (dir.), Historia de la iglesia en España, V. La Iglesia en la España Contemporánea (1808-1975), Madrid, BAC, 1979, p. 84

2 Casos muy notorios de protesta ante lo que se consideró extralimitación del poder del rey fueron los del obispo de Cuenca, Isidro Carvajal y Lancaster. Vid. Teófanes Egido, "El regalismo y las relaciones Iglesia-Estado en el siglo XVIII", en Ricardo Garcia Villoslada (dir.), Historia de la Iglesia en España, IV. La Iglesia en la España de los siglos XVII y XVIII, Madrid, BAC, 1979, p. 205, y C. C. Noel, "Opposition to Enlightened Reform in Spain: Campomanes and the Clergy, 17651775", Societas, III, 1973, pp. 30-31; y el del arzobispo de Valencia. Armando Alberola y Enrique Giménez, "Los alborotos antifranceses de Valencia y la huida del arzobispo Fabián y Fuero", Studia Historica. Historia Moderna, vol. XII, 1994, pp. 91-112.

3 Algunos estudios muy bien fundamentados empíricamente, como el de Luis Alonso Tejada, Ocaso de la Inquisición en los últimos años del reinado de Fernando VII, Madrid, ZYX, 1969, han llegado a afirmar que la ruptura fue propiciada "por el fanatismo anticlerical de masones y comuneros" (p. 35). Por el contrario, Modesto Lafuente, Historia General de España, Barcelona, Montaner y Simón, 1922, tomo 18, p. 251, carga la culpa en el lado eclesiástico: "Creer que (...) el clero, fuerte todavía por su organización e influencia, activo por su carácter, exclusivista por interés, y halagado por el reciente absolutismo de los seis años [1814-1819], hubiera de amoldarse impasible a instituciones que contrariaban sus hábitos y quebrantaban su influjo, era no conocer el espíritu de clase, la fuerza de la tradición, y la natural resistencia del egoísmo."
} 
En 1820 tuvo lugar una tensa controversia entre las autoridades civiles y la jerarquía católica. Los temas de discusión mantuvieron relación con la disciplina eclesiástica, pero en el fondo el debate no versó sobre la religión y la cultura católica, que nadie puso en duda, ni sobre materias teológicas, sino sobre politica. ${ }^{4}$ En rigor, fue una disputa por el poder. La revolución española elevó la soberanía de la nación por encima de todo, pero la misma Constitución que así lo estableció de forma inequívoca en su artículo 3, proclamó en el 12 el carácter católico e intolerante de esa nación, y mantuvo la monarquía como forma de gobierno. Ahora bien, en la España de ese tiempo era casi imposible el equilibro entre los poderes de la nación, del rey y de la Iglesia. Fernando VII perpetró en 1814 un golpe de Estado contra el sistema constitucional, y al margen de la retórica al uso, durante los años siguientes proporcionó abundantes pruebas de que no pretendía volver al Antiguo Régimen, sino establecer una nueva politica autoritaria, sin tolerar limites a la potestad real, provinieran de la Iglesia o de alguna forma de representación nacional establecida por un texto constitucional. ${ }^{5}$ La jerarquía eclesiástica española, por su parte, había sido renovada en un $80 \%$ en el sexenio 1814-1819, y salvo muy contadas excepciones, la integraban individuos opuestos al liberalismo, al tiempo que los clérigos sospechosos de simpatizar con esta opción politica habian perdido toda influencia, unos relegados a puestos sin relevancia u obligados a abandonar sus cargos -no pocos fueron recluidos en monasterios o conventos-, otros forzados al exilio para garantizar su integridad personal. 6 Por lo demás, si bien el papa Pío VII y su secretario de Estado Ercole Consalvi, ambos de talante ilustrado, pertenecian al grupo de los "politicanti", esto es, el sector de la Curia romana dispuesto a transigir con algunas novedades del nuevo tiempo siempre que no alteraran los principios religiosos y los derechos de la Iglesia, ambos eran decididos partidarios de la monarquía absoluta como forma de gobierno. ${ }^{7}$

Así pues, el sistema constitucional establecido en 1820 se halló frente a la poderosa oposición del rey y de los jerarcas de la Iglesia. El juramento de la Constitución por uno y otros no fue más que un acto formal, pues ambos eran radicalmente contrarios a los principios liberales. Fernando VII siempre estimó

4 Genis Barnosell, "God and Freedom: Radical Liberalism, Republicanism and Religion in Spain, 1808-1847”, International Review of Social History, n 57, 2012, p. 3.

5 Miguel Artola, Antiguo Régimen y revolución liberal, Barcelona, Ariel, 1978, p. 188; Emilio La Parra, Fernando VII. Un rey deseado y detestado, Barcelona, Tusquets, 2018, pp. 279-281.

${ }^{6}$ Manuel Teruel Gregorio de Tejada, Obispos liberales. La utopía de un proyecto (1820-1823), Lleida, Milenio, 1996, p. 223. Sobre la persecución del clero liberal durante el Sexenio Absolutista existen abundantes estudios. Véase, entre ellos, Ignacio Lasa Iraola, "El primer proceso de los liberales", Hispania, $\mathrm{n}^{\circ}$ 115, pp. 327-383; Emilio La Parra, "Antonio Bernabéu, un clérigo constitucional", Trienio, $\mathrm{n}^{\circ}$ 3, 1984; Gérard Dufour, Un liberal exaltado en Segovia: el canónigo Santiago Sedeño y Pastor (1769-1823), Valladolid, Secretariado de Publicaciones de la Universidad de Valladolid, 1989; Luis Barbastro, "El catolicismo liberal de Villanueva, Bernabéu y Cortés. Una contribución decisiva al primer liberalismo (1808-1823), Spagna Contemporanea, $\mathrm{n}^{\circ} 26,2004$; Vicente León Navarro, (2003), La pasión por la libertad. Miguel Cortés y López (1777-1854). Diputado a Cortes y diputado provincial, Valencia, Biblioteca Valenciana, 2003; Germán Ramírez Aledón (ed.), Valencianos en Cádiz. Joaquín Lorenzo Villanueva y el grupo valenciano en las Cortes de Cádiz, Cádiz, Fundación Municipal de Cultura, 2008; Julián Recuenco, "Ilustración y liberalismo en la diócesis de Cuenca (1750-1833", Hispania Nova, nº 5, 2005.

7 Roberto Regoli, Ercole Consalvi. Le scelte per la Chiesa, Roma, Pontificia Università Gregoriana, 2006 
que el sistema liberal era el mayor enemigo de la realeza, y tildó de republicana a la Constitución de 1812. La jerarquía eclesiástica achacó a la política liberal, tenida por heredera de la "filosofia" y de la incredulidad, el propósito de perseguir al clero y someter a la Iglesia, lo cual, según su planteamiento, supondria en definitiva el fin del catolicismo.

Antes de examinar los términos en que se desarrolló el enfrentamiento entre el constitucionalismo y la jerarquía de la Iglesia (no me ocuparé aquí del rey, el otro referente fundamental del poder), interesa tener en cuenta dos notas resaltadas en estudios recientes. Primera: los planes de reforma eclesiástica ideados por los ilustrados y primeros liberales no pusieron en duda el dogma católico, ni, por supuesto, pretendieron establecer otra religión distinta a la católica; es más, el artículo 12 de la Constitución declaró el catolicismo religión del Estado y estableció la intolerancia de cultos. ${ }^{8}$ Segunda: el clero español no era un cuerpo homogéneo social e ideológicamente ni en sus estratos más bajos ni en los más elevados, pero después de la depuración experimentada a partir de 1814 , su jerarquía se habia decantado mayoritariamente contra el liberalismo.

El notable esfuerzo reformista en materia eclesiástica desarrollado desde la segunda mitad del siglo XVIII pretendió conformar una Iglesia dedicada esencialmente a la actividad pastoral, alejada de los asuntos político-jurídicos. Los fundamentos de este modelo fueron el episcopalismo (el gobierno de la Iglesia debe estar en manos de los obispos, auxiliados por el clero secular; el papa, como obispo de Roma, posee la dignidad de primus inter pares), la religiosidad interior, tildada en la época de "jansenista" (vuelta a la iglesia pobre de los tiempos apostólicos, prioridad de la oración y de la caridad frente a los actos externos de devoción), y el regalismo (el poder temporal es competente para regular los asuntos materiales de la Iglesia, es decir, para intervenir en la "disciplina externa", en la cual, además de los temas económicos, ocupaba un lugar importante la organización y distribución del clero). ${ }^{9}$

Los estudios sobre este proceso han demostrado que el impulso renovador no provino del cuerpo eclesiástico, sino del Estado, el cual contó con la colaboración de una parte de la jerarquía eclesiástica y con la fidelidad de una élite administrativa de nuevo cuño dispuesta a fortalecer el poder del Estado

\footnotetext{
8 La intolerancia de cultos no constituyó un problema para el primer liberalismo, tanto por razones históricas y coyunturales, como porque la prioridad la tuvo la nación, la construcción de una voluntad política común compartida por la generalidad. Jesús Millán y Maria Cruz Romeo, "Iglesia y religión en el liberalismo anterior a la sociedad de masas", en Salvador Calatayud et al., El Estado desde la sociedad. Espacios de poder en la España del siglo XIX, Alicante, Publicaciones Universidad de Alicante, 2016, p. 153. Sobre el significado de la confesionalidad de la nación en el primer liberalismo vid. Emilio La Parra, "Cultura católica: confesionalidad y secularización", en Miguel Ángel Cabrera y Juan Pro (coords.), La creación de las culturas politicas modernas, 18081833, Madrid-Zaragoza, Marcial Pons-Prensas Universidad de Zaragoza, 2014, pp. 140-148.

9 Joël Saugnieux, Foi et Lumières dans l'Espagne du XVIII e. siècle, Lyon, PUL, 1985, pp. 27-33; Teófanes Egido, "La religiosidad de los ilustrados", en Historia de España fundada por Menéndez Pidal, T. XXXI-1, Madrid, Espasa-Calpe, 1987, p. 404-405; Emilio La Parra, "La Iglesia imaginada por los primeros liberales", en J. M. Delgado Idarreta y J.L. Ollero Valdés (eds.), El liberalismo europeo en la época de Sagasta, Madrid, Biblioteca Nueva-Fundación Práxedes Mateo Sagasta, 2009.
} 
frente a la aristocracia y el clero ${ }^{10}$. Los avances reformistas no fueron despreciables, en particular durante las Cortes de Cádiz (supresión de la Inquisición y de ciertos privilegios fiscales del clero, reglamentación de las órdenes religiosas, desamortización de algunos bienes eclesiásticos, planes de reforma de la enseñanza, primeros pasos en la secularización de la beneficencia, etc.), pero quedaron pendientes asuntos de envergadura, como la renovación del episcopado, la regularización de los bienes eclesiásticos, la adecuación del fuero eclesiástico al marco constitucional, la organización del sistema beneficial y la reforma de las órdenes religiosas. Estos fueron, entre otros, los asuntos que especialmente ocuparon la atención durante el Trienio Liberal.

El esfuerzo reformista, y el debate al que dio lugar, realmente importante -es abundantísimo el número de estudios al respecto, por lo que excuso su mención aquí- acentuó las históricas divisiones internas del clero (alto y bajo, seculares y regulares, disputas entre sí de las distintas órdenes religiosas, adversarios y partidarios de los jesuitas, tomistas y antitomistas, etc.). En cuanto a su posición política, se podría decir que en 1820 el cuerpo eclesiástico español se había fracturado en dos bloques casi irreconciliables. En uno se situaron quienes aceptaron el programa reformista $y$, en consecuencia, estimaron que la Constitución liberal y la política basada en ella eran compatibles con la religión y con la Iglesia católica; son los llamados clérigos liberales. El otro lo formó el grueso del clero tradicional, el cual no aceptó esa compatibilidad, y por tanto, consideró que el resultado de la política liberal sería la destrucción del cuerpo eclesiástico y, en consecuencia, de la Iglesia y el catolicismo. ${ }^{11}$

A medida que vamos conociendo la biografia de los eclesiásticos de este tiempo sabemos que se dieron muchos matices en uno y otro bloque, y que algunos individuos cambiaron de postura con el tiempo. El cardenal Borbón pasó de ser "el cardenal de los liberales" a quedar integrado en el grupo de los obispos realistas; el obispo de Barcelona Pablo Sichar recibió muchas alabanzas de los liberales de aquella ciudad por su apoyo inicial al constitucionalismo, pero finalmente fue deportado a las Baleares, tachado de contrarrevolucionario. ${ }^{12}$ Por lo demás, no todos los individuos susceptibles de ser calificados de "clérigos liberales" asumieron por entero el ideario político liberal (caso relevante es el de Joaquín Lorenzo Villanueva), los tildados de jansenistas, así como algunos episcopalistas, no siempre aplaudieron la politica regalista. En el otro bloque primó el temor a la revolución, pero algunos no rechazaron de plano ciertas reformas eclesiásticas destinadas a eliminar vicios históricos, extremo este que quedó patente en las respuestas a la Consulta al País de 1809. Las dos

10 Las características de esta élite y su ideario en Antonio Calvo Maturana, Cuando manden los que obedecen. La clase politica e intelectual de la España preliberal (1780-1808), Madrid, Marcial Pons, 2013.

11 Gérard Dufour, Estudio preliminar a Sermones revolucionarios del Trienio Liberal, Alicante, Instituto de Cultura Juan Gil-Albert, 1991, pp. 38 ss. ha distinguido tres tipos de eclesiásticos en el Trienio, según su posición política: los partidarios del absolutismo, los que aceptaron la Constitución, y los prudentes, es decir, quienes se pronunciaron a favor o en contra del constitucionalismo según la ocasión.

12 Carlos Rodríguez López-Brea, Don Luis de Borbón, el cardenal de los liberales (1777-1823), Toledo, Junta de Comunidades de Castilla-La Mancha, 2002; Gérard Dufour, "Política y religión en el Diario Constitucional de Barcelona", en Rafael Serrano García et al., Dimensiones religiosas de la Europa del Sur (1800-1875), Valladolid, Universidad de Valladolid, 2018, pp. 48-50. 
preocupaciones más graves de los situados en este segundo bloque fueron que el poder temporal se impusiera al eclesiástico, y que las reformas llegaran demasiado lejos, hasta parecerse a lo sucedido en Francia, donde -según elloslos seguidores de los "filósofos" se hicieron regicidas, y tras acabar con la monarquía, con la Iglesia, y con los eclesiásticos, sembraron la impiedad y el desorden (en apoyo de esta tesis siempre se mencionó, como una especie de referencia ineludible, la Constitución Civil del Clero de 1790). Para muchos clérigos tradicionales, los liberales españoles eran émulos de los revolucionarios franceses, y si bien no se atrevian a ser tan directos como los ultra pirenaicos, su objetivo venía a ser el mismo. ${ }^{13}$

\section{II: DISTANCIAMIENTO ENTRE LOS DOS PODERES}

La experiencia de las Cortes de Cádiz hizo saltar las alarmas en la jerarquía eclesiástica española, y también en Roma. Las reformas decretadas y el debate público sobre asuntos religiosos en el parlamento o en la prensa, al amparo de la ley de libertad de imprenta decretada en 1810, escandalizaron y desbordaron al clero tradicional. Acostumbrado a dominar doctrinalmente el espacio público, este no podía tolerar que en los papeles que corrían de mano en mano hasta llegar a un gran número de personas se opinara sobre cuestiones hasta entonces reservadas al cuerpo eclesiástico, o en el peor de los casos, a una selecta minoría laica. Todo esto era el resultado de la nueva politica, inaceptable para quienes estaban convencidos de que el orden existente, el orden natural creado por Dios, era inmutable.

Es comprensible, en consecuencia, que a pesar de la declaración de confesionalidad e intolerancia religiosa del artículo 12, buena parte del clero recibiera con recelo la Constitución. Incluso levantó suspicacias ese artículo, tan favorable aparentemente a la Iglesia, pues terminaba diciendo que "la nación la protege [a la religión católica, apostólica, romana] con leyes sabias y justas." Esto suponía, ni más ni menos, la elevación del regalismo a precepto constitucional. Según el texto constitucional, solo podía dar leyes la nación, en la que residía esencial y originariamente la soberanía; en consecuencia, únicamente ella estaba capacitada para determinar la religión del Estado y tolerar o prohibir cultos. Esta interpretación del artículo 12 la explicitaron los liberales en el importante Dictamen sobre la abolición de la Inquisición presentado a las Cortes el 8 de diciembre de 1812: la prohibición de otros cultos distintos al católico y la declaración de confesionalidad del Estado no se fundaban en principios religiosos, sino en el poder constituyente de la nación. La religión católica no es tolerante ni intolerante, afirmaba este texto: "la ley civil es la que únicamente admite o excluye de los Estados la diversidad de religiones, porque es propio y peculiar de toda nación examinar y decidir lo que más le conviene, según las circunstancias, designar la religión que debe ser fundamental y protegerla con

13 No solo la Iglesia española, sino la católica en general, consideró que con medidas como la Constitución Civil del Clero, la Declaración de Derechos y otras decisiones, la Revolución francesa había causado una fractura profunda en la concepción de la sociedad presente en la tradición católica. Daniele Menozzi, Iglesia y derechos humanos. Ley natural y modernidad politica, de la Revolución francesa a nuestros dias, Zaragoza, Prensas de la Universidad de -Zaragoza, 2019, pp. 12-13. Véase, asimismo, Andoni Artola Renedo y Antonio Calvo Maturana, "Declinaciones de la reacción eclesiástica contra la Revolución Francesa en España (1789-1808)", Hispania, 2017, n 256, pp. 437-469. 
admisión y exclusión de cualquiera otra."14 En el transcurso del debate del mencionado Dictamen, Muñoz Torrero remachó esta idea: el establecimiento de la intolerancia religiosa es una medida "puramente política, y con el objeto de mantener la unión y concordia entre los ciudadanos..."15 y como cualquier otra decisión política era susceptible de modificación. Por supuesto, los diputados realistas o "serviles" defendieron lo contrario. Un mes antes de las palabras de Muñoz Torrero, el entonces canónigo Pedro Inguanzo había mantenido que la religión "debe ser protegida no por leyes conformes a la Constitución, sino por leyes conformes a la religión, esto es, protegiendo su enseñanza y los cánones y disposiciones de la Iglesia con todos sus auxilios que necesiten, sean o no aquellos conformes o disconformes a las leyes civiles."16

Las posturas estaban perfectamente delimitadas. Los liberales abogaban por la secularización de la política, lo que dada la no separación entre Estado e Iglesia conducia en la práctica al regalismo. Por el contrario, los "serviles" defendieron la sujeción de las leyes a los preceptos religiosos y se opusieron en la medida de sus posibilidades a las reformas eclesiásticas, alegando que solo la Iglesia tenía competencia en la materia, extremo este último que repetirán hasta la saciedad durante el Trienio.

Tras el golpe de Estado de Fernando VII en 1814, el clero tradicional atacó insistentemente a la Constitución, que incluso fue denunciada ante la Inquisición. Este sector del clero trató de demostrar, ante todo, que el principio de la soberanía nacional era una especie de levantamiento contra Dios, impulsado por hombres desvariados por la "filosofia" y la anarquía. Al mismo tiempo, abogó por un nuevo sistema monárquico, que ya no era el del siglo XVIII, tan funesto, precisamente porque el regalismo habia sido uno de sus rasgos dominantes, sino una vuelta a la monarquía tradicional católica de sesgo medieval, en la que la potestad de la Iglesia tenía primacía sobre la de los reyes incluso en los asuntos temporales, como planteaban en Francia De Bonald y De Maistre, autores muy leídos en España. Esta doctrina, basada en una concepción teocrática del poder, fue ampliamente difundida a través de sermones -algunos fueron impresos y gozaron de varias ediciones- y todo tipo de escritos. ${ }^{17}$ Entre estos últimos alcanzó gran predicamento en los medios eclesiásticos la obra del capuchino Rafael de Vélez: Apología del altar y del trono, editada en $1818 \mathrm{y}$ convertida desde entonces en una especie de vademécum del clero tradicional. Entre otras cosas, Vélez afirmaba que si llega a durar mucho la "protección" declarada en el artículo 12 de la Constitución, "no queda fraile, convento, canónigo, obra pía, rentas eclesiásticas, que no se hubieran abolido", "el artículo que parece de vida para la Iglesia es como un decreto de muerte". ${ }^{18}$ Aunque a todas luces exagerada, esta crítica resultó muy eficaz.

14 Diario de Sesiones de las Cortes Generales y Extraordinarias, Madrid, Imprenta de García, 1870, sesión del 8 de diciembre de 1812, pág. 4190.

15 Diario de Sesiones de las Cortes, op. cit, sesión del 15 de enero de 1813, p. 4340.

16 Diario de Sesiones de las Cortes, op. cit., sesión del 8 de diciembre de 1812, p. 4244.

17 Javier López Alós, Entre el trono y el escaño. El pensamiento reaccionario español frente a la revolución liberal (1808-1823), Madrid, Cortes Generales, 2011, pp. 241-248; Emilio La Parra, Fernando VII, op. cit., pp. 284-290.

18 Rafael de Vélez, Apología del Altar y del Trono, Madrid 1818, I, p. 205, cit. por Manuel Revuelta, "La confesionalidad del Estado en España", en E. La Parra y J. Pradells (eds.), Iglesia, 
En este ambiente de combate, es difícil imaginar que en 1820 el clero, y especialmente su jerarquía, recibiera de buen grado el restablecimiento de la Constitución. Con ella retornaba la politica regalista en su peor versión, pues despojado de su soberanía de origen divino, el rey no mantendría la primacía politica, que pasaba a unas Cortes que presumiblemente estarian dominadas por los liberales. De nuevo tendrian amplio margen de maniobra aquellos clérigos "jansenistas" que en la legislatura de 1810 habian marcado la pauta reformista en asuntos religiosos, los Muñoz Torrero, Joaquín Lorenzo Villanueva y demás, a quienes ahora se unirian otros de la "secta", como Antonio Bernabéu o García Page. Tampoco la Santa Sede acogió con satisfacción las noticias sobre la insurrección de los militares encabezados por Rafael del Riego. E1 29 de febrero de 1820, cuando aún no estaba decidido el triunfo de la sublevación, el cardenal Consalvi, secretario de Estado de la Santa Sede, en nota al nuncio Giacomo Giustiniani calificó el acontecimiento de "acto inmoral", porque atentaba contra la soberanía absoluta del rey. La misma opinión, pero con mayor contundencia, había expuesto dos semanas antes Giustiniani en uno de sus despachos: "Dios no querrá permitir jamás que triunfe, en daño de la religión y del augusto príncipe que la protege, la causa de los rebeldes". ${ }^{19}$

El clero, con todo, cumplió el decreto de 9 de marzo de 1820, que ordenaba jurar la Constitución a todas las autoridades. Tal comportamiento estuvo determinado por la tradicional inclinación a acatar y seguir el ejemplo de la autoridad reconocida-Fernando VII había jurado ese mismo día. También influyó el pragmatismo político de Pío VII y su secretario de Estado Consalvi. A pesar de su opinión sobre el levantamiento de Riego, una vez juró el rey, Consalvi dio instrucciones a Giustiniani para que el clero español obedeciera la disposición civil. El nuncio, a su vez, instó al cuerpo eclesiástico español a prestar el juramento, alegando que la negativa era un acto "imprudente"; además, no encontraba en la Constitución nada contrario a la religión. Así pues, algunos eclesiásticos inicialmente reticentes, como los arzobispos de Santiago y Zaragoza, y los obispos de Zamora y Málaga, acataron finalmente la orden de la autoridad civil. $^{20}$

El cumplimiento del trámite de la jura no debe ocultar el malestar del clero ante el nuevo régimen. Al menos esa fue la percepción del embajador francés, quien a finales de marzo de 1820 informó a su ministro de Asuntos Exteriores que el clero asumía muy lentamente la Constitución, que evidentemente le

Sociedad y Estado en España, Francia e Italia (ss. XVIII-XX), Alicante, Instituto de Cultura juan GilAlbert, 1992, p. p. 380.

19 Nota de Consalvi al nuncio del 29 de febrero de 1820 y Despacho de Giustiniani del 15 de ese mes, cit. por Maximiliano Barrio, La Santa Sede y los obispos españoles en el Trienio Liberal (1820-1823), Roma, Iglesia Nacional Española, 2015, p. 18.

20 Despacho de Giustiniani del 2-4-20, cit. por Luis Alonso Tejada, Ocaso de la Inquisición..., op. cit. p. 32; Real Decreto de 26 de marzo de 1820, en Juan Muñiz Miranda, Colección oficial de las Leyes, Reales disposiciones y Circulares de interés general expedidos por el rey D. Fernando VII y por las Cortes en el año de 1820, Madrid, Imprenta de José Morales, 1853, p. 77; Maximiliano Barrio, La Santa Sede y los obispos...,op. cit., pp. 17-20 y p. 51. No cabe descartar que hiciera mella en algunos eclesiásticos el Real Decreto de 26 de marzo, por el que se penalizaba a quienes se resistiesen a jurar la Constitución "o lo hicieran con protestas contrarias a la misma", en Muñiz Miranda, Colección...op. cit., p. 77. 
repugnaba. ${ }^{21}$ No estaba en este caso la totalidad del clero, pues el tildado de liberal la celebró, pero según todas las pruebas, el rechazo fue mayoritario entre la jerarquía, la cual lo manifestó de palabra y de hecho. ${ }^{22}$ Desde el primer momento llegaron al Gobierno informes sobre actuaciones anticonstitucionales protagonizadas por miembros del alto clero. De ello se hizo eco el ministro de Gracia y Justicia, García Herreros, en su primera memoria a las Cortes, leída el 11 de julio de 1820, dato que manifiesta la importancia politica que le atribuía. El ministro dio cuenta de un informe del jefe político de Sevilla, en el que denunciaba movimientos contra el sistema constitucional en esa ciudad, en los cuales estaban implicados clérigos notorios: "Canónigos y prebendados de esta catedral hay que tienen contra sí la opinión general; en todo tiempo dieron pruebas de servilismo y de ser tan supersticiosos en la religión como en la politica: he tenido de ellos mil quejas, ya por conversaciones que tuvieron, ya por desagrado que manifestaron, ya por otros signos con que dieron a entender estaban mal hallados con el orden constitucional: el pueblo dirigia a ellos sus invectivas..." Esto, por sí solo, resultaba suficientemente preocupante, pero lo que quizá alarmó más al gobierno fue un anónimo difundido en Sevilla, también recogido por el ministro en su memoria. Decía así: "Sacerdotes prostituidos, vuestras intrigas se han descubierto: persuadios que la primera sangre que va a derramarse es la vuestra si hay el menor alboroto o reacción (...); y no toméis el sagrado nombre de la religión para solapar vuestras comodidades. Venganza eterna a vosotros."23

Incidentes de esta naturaleza proliferaron por el pais, creando un ambiente de enfrentamiento social poco propicio para iniciar el nuevo régimen. Ello movió a las autoridades civiles a tomar medidas contra ciertos eclesiásticos, entre quienes abundaron los canónigos, consistentes las más de las veces en el destierro de sus lugares de residencia o en la reclusión en algún convento o monasterio. ${ }^{24}$

\section{LA OFENSIVA POLÍTICA DEL NUNCIO GIUSTINIANI}

La Junta Provisional, órgano encargado de organizar la transición al régimen constitucional, presidido por el primado de España, cardenal Luis de Borbón, se ocupó desde el primer momento de los asuntos religiosos. El 9 de marzo de 1820,

21 Despacho de Montmorency-Laval al Ministro de Asuntos Exteriores de Francia, Madrid, 27 de marzo de 1820. Archives Diplomatiques, Correspondance politique. Espagne, T. 705, f. 197.

22 Carlos Rodríguez-López Brea, Don Luis de Borbón...op. cit., p. 290.

23 Memoria del ministro de Gracia y Justicia Antonio García Herreros, Congreso de los Diputados, Diario de Sesiones. Legislatura de 1820 (ed. digital), sesión del 11 de julio, pp. 70-71.

24 No es posible detenerse aquí en relacionar casos concretos. Basten dos datos, además de lo apuntado sobre Sevilla. El 29 y 30 de abril (es decir, al mes siguiente de realizarse en todas partes el juramento constitucional), el jefe político de Galicia ordenó la deportación de 44 sospechosos de colaborar en conspiraciones realistas, entre los que se contaban 7 canónigos, 2 sacerdotes y 4 religiosos. Xosé R. Barreiro, Liberales y absolutistas en Galicia, Vigo, Edicións Xerais de Galicia, 1982, pp. 61-62; José A. Vázquez Vilanova, Clero y sociedad en la Compostela del siglo XIX, Santiago, CSIC-Instituto Padre Sarmiento, 2004, pp. 209 y 211. Meses más tarde, informaba el embajador francés que en Madrid cada día se descubrian trazas de maniobras contra el régimen constitucional y en ellas siempre se encontraban comprometidos eclesiásticos ("prêtres"). Despacho de Montmorency-Laval del 7 de agosto de 1820, Archives Diplomatiques, Correspondance politique. Espagne, T. 76, f. 317. 
día de su formación, renovó el decreto del 22 de febrero de 1813 que suprimía la Inquisición. En coherencia con ello, y de acuerdo con la ley de libertad de imprenta restablecida al dia siguiente, puso el control de las publicaciones en manos de la autoridad civil: ordenó que las listas de libros contrarios a la religión elaboradas por los obispos pasaran al Ministerio de la Gobernación, el cual, previo dictamen de la Junta de Censura y del Consejo de Estado, las enviaria a las Cortes para su aprobación. El 27 de marzo prohibió la admisión de novicios en la Compañía de Jesús, ordenó la reducción de las casas existentes de este instituto a una sola por localidad, el cese de la enseñanza en sus colegios y la administración de las temporalidades de la Compañía por el crédito público. El 3 de abril reiteró la orden de 1812 sobre la supresión del llamado Voto de Santiago. Un Real Decreto del 21 de ese mes puso en vigor las secularizaciones de religiosos concedidas en España por los obispos durante el tiempo de incomunicación con la Santa Sede en la época de la guerra contra Napoleón. El 7 de mayo se suspendió toda nueva profesión en las comunidades religiosas hasta que las Cortes decidieran sobre la reforma general de las mismas, y se les prohibió vender cualquier parte de sus bienes. ${ }^{25}$

Esta política no era novedosa. Consistía simplemente en el restablecimiento de la obra de las Cortes de Cádiz, anulada por Fernando VII en 1814. La Junta Provisional no trató otras cuestiones relevantes, y remitió la resolución de las pendientes a las futuras Cortes, las cuales prosiguieron la misma politica desde el inicio de sus sesiones el 9 de julio de 1820. Su primera decisión de enjundia consistió en la supresión de la Compañia de Jesús (17 de agosto). El 2 de septiembre ordenaron que los eclesiásticos que gozaran de más de un beneficio eligieran el que más le acomodase, declarando vacantes los restantes. El 26 de ese mes fue anulado el fuero personal de los eclesiásticos, de manera que quedaban sujetos a la justicia ordinaria quienes cometieran un delito merecedor de penas corporales, esto es -según especificó el decreto- las de cárcel, extrañamiento del reino, galeras, vergüenza pública, etc. Al día siguiente, las Cortes suprimieron "toda especie de vinculaciones", y prohibieron expresamente que los establecimientos conocidos como "manos muertas" adquirieran bienes raíces o inmuebles por testamento, donación o por otro título oneroso o lucrativo, e impusieran capitales de censo sobre bienes raíces. Con todo, la decisión más relevante de estas primeras Cortes del Trienio fue el decreto del 1 de octubre de 1820, titulado: "Supresión de monacales y reforma de regulares", que declaró extinguidos los monasterios de las órdenes monacales, los conventos y colegios de las Órdenes Militares, y los canónigos regulares de San Benito, San Agustín y premonstratenses. En cuanto al resto de las órdenes religiosas se dispuso que solo existiera un convento por localidad si contaba con un número mínimo de frailes ordenados "in sacris". Todos los religiosos quedaban sujetos a la jurisdicción del obispo de la diócesis y los bienes de los establecimientos pasaban al crédito público. A partir del último trimestre de 1820 las Cortes solo tomaron dos nuevas medidas de envergadura sobre la Iglesia, ambas en 1821: la prohibición del pago a Roma por la expedición de bulas de obispos, dispensas matrimoniales, rescriptos o por otros procedimientos (17 de abril), importante

25 Las disposiciones mencionadas en Juan Muñiz Miranda, Colección...op. cit. Vid. también Blanca E. Buldain Jaca, Régimen politico y preparación de Cortes en 1820, Madrid, Congreso de los Diputados, 1988, pp. 217-220. 
reivindicación histórica del reformismo ilustrado, y la reducción del diezmo a la mitad (29 de junio). ${ }^{26}$

La política religiosa del nuevo régimen inquietó considerablemente a la Santa Sede. El 27 de mayo de 1820, sin esperar a la reunión de las anunciadas Cortes, a las cuales correspondía según la Constitución marcar la orientación política del nuevo régimen, Pío VII creó una Congregación especial de cardenales para los asuntos eclesiásticos de España. ${ }^{27}$ No bastaban los organismos ordinarios de la Curia romana, porque la situación española fue considerada excepcional.

La primera reunión de esta Congregación especial tuvo lugar el 12 de junio de 1820, y la última -sin secretario ni consultores- el 30 de mayo del año 1823, cuatro días después de la formación en Madrid por el duque de Angulema de una Regencia realista encargada de gobernar en nombre de Fernando VII, "cautivo de los liberales". La Congregación especial estuvo activa, pues, durante todo el Trienio Liberal. En ella se deliberó sobre la supresión de la Inquisición, la libertad de prensa, las disposiciones sobre bienes eclesiásticos, la reforma de las órdenes religiosas, la supresión del voto de Santiago, la inmunidad eclesiástica, la celebración de un concilio nacional, los nombramientos de obispos tildados de liberales y el exilio de los contrarios al régimen, el establecimiento del medio diezmo..., en suma, se examinaron todas las decisiones sobre asuntos eclesiásticos del régimen constitucional español. También se debatió in extenso, aunque evidentemente con retraso (se hizo el 8 de agosto de 1820) sobre la licitud del juramento de la Constitución.

Salvo en lo relativo al juramento de la Constitución, la Congregación especial se pronunció en contra de las medidas de las autoridades políticas españolas. Actuó como organismo vigilante y censor del régimen político español, y sin embargo no emitió una condena formal y explícita del mismo, que aceptó como mal menor. Esta actitud quizá fue producto de la coyuntura política europea. Tras la recuperación por el papado de su dominio temporal sobre los Estados Pontificios, una vez desaparecido Napoleón de la escena política, la Santa Sede estaba obligada a mantenerse fiel al principio diplomático de neutralidad política. ${ }^{28}$ No obstante, la Congregación especial dejó patente en sus conclusiones que España se había dejado llevar por los enemigos de la religión: el jansenismo, el episcopalismo, el regalismo y la "filosofia". Con este juicio rechazaba de plano el proyecto de Iglesia del primer liberalismo y, en definitiva, censuraba por entero la obra del régimen constitucional español. Lo hizo el propio Pío VII en carta personal a Fernando VII en septiembre de 1820: las medidas en materia religiosa adaptadas hasta entonces -escribió el papa- eran “desórdenes” que amenazaban

26 No nos detendremos aquí en el análisis de las medidas mencionadas. De ello se han ocupado dos reputados especialistas: Manuel Revuelta, Politica religiosa de los liberales en el siglo XIX. Trienio Constitucional, Madrid, CSIC, 1973, pp. 121-292, y Maximiliano Barrio, La Santa Sede y los obispos españoles...op. cit., pp. 71-145.

27 Sobre la Congregación Especial, véase Manuel Teruel, Obispos liberales...op. cit., pp. 91-105; Roberto Regoli, "La Congregación Especial para los Asuntos Eclesiásticos de España durante el trienio liberal (1820-1823)", Anuario de Historia de la Iglesia, 19, 2010, pp. 141-166; y Maximiliano Barrio Gozalo, La Santa Sede y los obispos españoles..., op. cit., pp. 24-32.

28 Roberto Rinaldi, Roma tra due reppubliche: il tempo del Papa-Re (1798-1848), Roma, Spada, 1991. 
a la religión y la Iglesia. ${ }^{29} \mathrm{El}$ secretario de Estado Consalvi fue más lejos en mayo de 1823, al calificar al régimen constitucional español de "enemigo que amenaza a Europa, y decidido enemigo de la religión, a la cual persigue."30

En la práctica, el objetivo concreto de la Santa Sede en los años del Trienio consistió en frenar la política reformista liberal y conseguir la unidad del episcopado español, entre sí y con el papa. El 15 de octubre de 1820 escribió Consalvi a Giustiniani: "Usted puede imaginar lo desagradable que resulta para el Santo Padre el ver la ruina hacia la que se encaminan irreparablemente los intereses de la Iglesia en ese Reino y el desorden que intenta adueñarse del sistema político. En lo que respecta a las cosas eclesiásticas, Su Santidad desea de su parte que impida todos aquellos males que puedan ser frenados, o al menos evitar que surjan..."31 Un mes más tarde, el mismo Consalvi completó su instrucción: "Lo scopo principale a cui Ella [el nuncio apostólico] debe ora dirigire tutte le sue mire, si è quello di incoragginare i Vescovi a sostenere i diritti della Chiesa, ed a mantenirsi nella più stretta unione col Summo Pontifice. Ella debe procurare che il Corpo Episcopale si penetri della necessità di essere in perfetta unione con tutti i suoi membri, e col Papa."32

La actuación del nuncio en Madrid era, pues, de la mayor importancia. Debía impedir "la ruina de la Iglesia", y actuar como nexo de unión de los obispos españoles, sin permitir la mínima disidencia respecto al papa ("mantenirse nella più stretta unione"). En suma, el nuncio recibió el encargo de ejercer in situ de director político de la jerarquía eclesiástica española frente a las autoridades civiles.

Giustiniani asumió con entusiasmo este cometido, y como ha señalado Maximiliano Barrio, lo desempeñó con un doble talante: como diplomático pragmático en sus negociaciones con ministros y diputados, para impedir o al menos paralizar las reformas; $\mathrm{y}$ como persona resentida frente a unas autoridades civiles que no atendieron sus requerimientos. ${ }^{33}$ En consecuencia, a medida que las Cortes decidieron sobre asuntos eclesiásticos, el nuncio se convirtió en un crítico tenaz del sistema constitucional. Su conducta política no se diferenció de la de los embajadores de las monarquías de la Santa Alianza (Rusia, Austria, Prusia y Francia). Todos condenaron el restablecimiento en España del nuevo régimen, tanto por la forma -la revuelta de militares traidores a su rey- como por fundamentarse en una Constitución contraria a los derechos del rey, que abría la vía hacia el republicanismo. La impresión general nada más iniciarse el nuevo régimen puede quedar resumida en el juicio expuesto por el embajador austriaco Brunetti en uno de sus despachos a Metternich: la revolución española es el resultado de hombres ambiciosos que desean fundar su

29 Carta de Pío VII a Fernando VII, 15 de septiembre de 1820, en Colección Eclesiástica Española, Madrid, Imprenta de Aguado, 1823-1824, T. I, pp. 33-39.

30 Cit. por Roberto Regoli, “La Congregación especial...”, op. cit., p. 163.

31 Despacho de Consalvi a Giustiniani, Roma, 15 de octubre de 1820, cit. por Maximiliano Barrio, La Santa Sede y los obispos...op. cit., p. 33.

32 Minuta de despacho de Consalvi a Giustiniani, Roma, 15 de noviembre de 1820, cit. por Roberto Regoli, "La Congregación especial...", op. cit. p. 164, nota 81.

33 Maximiliano Barrio, La Santa Sede y los obispos españoles...op. cit., p. 33-34. 
fortuna sobre la ruina del trono y del altar. ${ }^{34}$ La coincidencia en el fondo, aunque no siempre en los procedimientos, del nuncio, y por ende la Santa Sede, con la politica de la Santa Alianza se mantuvo hasta el final. Ciertamente, como ha quedado dicho la Santa Sede no condenó formalmente el régimen constitucional español, pero coincidió con los gobiernos que lo derrocaron por la fuerza de las armas.

La actuación más destacada y visible del nuncio en 1820, año al que limitaré mis consideraciones en lo referente a su actividad diplomática, consistió en el envío de notas de protesta al Gobierno. No hubo decisión en materia eclesiástica de la Junta Provisional y luego de las Cortes que no contrarrestara Giustiniani con el correspondiente escrito. En total mandó 32 notas, la primera el 27 de abril de 1820 sobre las secularizaciones concedidas por los obispos españoles durante el tiempo de la Guerra de la Independencia; la última, del 12 de enero de 1823, también se refirió a este asunto, en este caso en contra del reconocimiento a los secularizados de la facultad de testar y heredar. ${ }^{35}$

Los argumentos utilizados por Giustiniani en estos escritos se diferenciaron muy poco de los que venía empleando el clero tradicional desde el siglo anterior para oponerse a cualquier medida que alterara su estatus: defensa permanente y con firmeza de la autoridad del papa sobre todas las Iglesias, negación de facultades al poder civil para intervenir en los asuntos eclesiásticos, y justificación de la propiedad y la inmunidad eclesiásticas. Fundamentó sus alegaciones en dos premisas. Primera: todo lo relacionado con el ámbito eclesiástico es sagrado y, por tanto, queda bajo la jurisdicción de la Iglesia. Segunda: no existe distinción entre disciplina externa e interna de la Iglesia. Ilustrados y liberales se habian basado en esta distinción para justificar el reformismo: el poder civil tenía facultad para regular los asuntos materiales de la Iglesia ("disciplina externa"), mientras que los espirituales ("disciplina interna") quedaban bajo la competencia exclusiva de la autoridad eclesiástica. Según el nuncio, esta distinción era ficticia. "Es punto y dogma capital de fe" afirmó, que solo existe una disciplina, cuya regulación corresponde en exclusiva a la autoridad religiosa. También negó "el derecho de protección de los príncipes" sobre la Iglesia invocado por los reformistas (y reconocido en el artículo 12 de la Constitución de 1812). Citando a Bossuet, mantuvo que el Estado no está por encima de la Iglesia, sino dentro de ella, y que la Iglesia es libre e independiente del poder civil. Por consiguiente, cualquier intervención del Estado en los asuntos eclesiásticos era una alteración del "orden inmutable establecido por Dios".36 Desde este presupuesto, toda decisión sobre esta materia adoptada por el poder civil sin contar con la autorización del papa -o en caso de delegación, de los

34 Despacho de Brunetti a Metternich, Madrid, 23 de febrero de 1820 (Archives Diplomatiques, Mémoires et documents, T. 308. En abril de 1820, el zar Alejandro I envió una circular a las cortes europeas condenando enérgicamente la revolución española e instando a una reacción conjunta, que no se produjo por el momento, pero el gabinete de Londres respondió con una nota confidencial, enviada a los gobiernos de Austria, Francia, Rusia y Prusia, en la que decía que la Constitución española "contiene apenas en su forma la apariencia de una monarquía." Agustín Argüelles, De 1820 a 1824. Reseña histórica, Madrid, 1864, p. 48.

35 Las notas del nuncio están recogidas cuidadosamente en Colección Eclesiástica Española, tomos I y II (el indice de las mismas en tomo II, pp. 179-182).

36 Nota del nuncio del 23 de septiembre de 1820 sobre disciplina eclesiástica (Colección Eclesiástica Española, I, pp. 113-128) 
obispos- constituía un ataque a la Iglesia, pues alteraba su disciplina (la única existente). Era, en suma, contraria al orden divino.

El nuncio no entró en sus notas en consideraciones sobre la conveniencia o no de acometer ciertas reformas. Se limitó a descalificar las decisiones de la autoridad civil, sin descuidar las relativas a la regulación de los bienes eclesiásticos. "La Divinidad -afirmó en una nota dedicada a este último asuntoes la única propietaria de los bienes de la Iglesia", de los cuales son custodios, dispensadores y usufructuarios sus ministros; dicho con otras palabras del mismo nuncio propias del extinto sistema señorial: el dominio directo es de Dios y el útil de la autoridad eclesiástica. Es más, "los bienes, aunque temporales en su esencia, llegan a ser espirituales por la sucesiva consagración que de ellos se hace."37 En definitiva, los legitimaba la historia. Ello no era obstáculo para que en situaciones especiales la Iglesia pudiera concurrir con sus bienes a las urgencias del Estado, pero siempre previo acuerdo con la autoridad eclesiástica. Sin este requisito, cualquier decisión sobre los bienes de la Iglesia era una apropiación indebida, una "usurpación", un "despojo" de su propiedad legítima, realizado con "violencia e injusticia". Y aun llega a decir Giustiniani que la reducción del diezmo a la mitad conllevaba tres pecados: sacrilegio, hurto e injusticia. ${ }^{38}$

En suma, según el nuncio ninguna decisión sobre materia eclesiástica adoptada por el poder civil estaba justificada, lo que traducido a la práctica politica significaba que las autoridades constitucionales españolas perseguian a la Iglesia y atentaban contra la religión que la Constitución decía garantizar. No puede quedar más patente la ruptura del representante de la Santa Sede con el régimen constitucional.

\section{PROTESTAS DEL EPISCOPADO}

La reacción del episcopado español ante la política del constitucionalismo no se diferenció de la del nuncio. Así pues, podemos hablar de la formación durante el Trienio Liberal de un frente de oposición constituido por el conjunto de la jerarquía eclesiástica, romana y española, frente que se incrementó y endureció con el paso del tiempo.

Al suprimir la Inquisición y establecer una nueva normativa sobre censura y circulación de impresos de acuerdo con la libertad de imprenta, el nuevo régimen enojó desde el primer momento y de manera considerable a los obispos. ${ }^{39}$ De pronto, estos se sintieron despojados de un poder ejercido históricamente casi sin contestación, y se apresuraron a publicar edictos y pastorales recordando a los fieles que seguian vigentes las prohibiciones dictadas por el Santo Oficio. E1 primero en reaccionar fue el obispo de Osma, Mariano de Cavia, hombre muy combativo contra el constitucionalismo, hasta el punto de que en 1823 fue

37 Nota sobre propiedad eclesiástica, 25 de septiembre de 1820 (Colección Eclesiástica Española, I, pp. 136-151)

38 "Segunda Nota del nuncio sobre la propiedad y otros objetos eclesiásticos", 30 de mayo de 1821 (Colección Eclesiástica Española, I, pp. 197-219)

39 Sobre el nuevo marco en materia de censura durante el primer liberalismo vid. las colaboraciones en Elisabel Larriba y Fernando Durán López (eds.), El nacimiento de la libertad de imprenta. Antecedentes, promulgación y consecuencias del Decreto de 10 de noviembre de 1810 , Madrid, Silex, 2012. 
miembro de la Regencia realista que desarrolló una intensa y durísima represión ${ }^{40}$. El 15 de marzo de 1820, solo seis dias después de haber sido abolida la Inquisición, publicó un edicto en el que decía: "Declaramos, pues, que subsisten en su fuerza y vigor las prohibiciones de leer libros de mala doctrina que han emanado de aquel tribunal autorizado legítimamente para dictarlas [la Inquisición]", y remachaba: "a mayor abundamiento, renovamos las mismas prohibiciones bajo las mismas penas espirituales..." ${ }^{41} \mathrm{El}$ obispo Cavia se permitía ignorar la decisión de la Junta Provisional, y de hecho daba por existente la extinta Inquisición, al menos en una de sus funciones principales, cual había sido la prohibición de publicaciones. Otros prelados hicieron lo propio, e inmediatamente inundaron el país de escritos sobre la misma materia. Tal envergadura alcanzó esta reacción episcopal, que el ministerio de Gracia y Justicia se vio obligado a recordar a los prelados mediante una circular la obligación de atenerse a la nueva legislación. Quienes no la han cumplido afirmaba el ministerio- "han carecido de luces... para distinguir los límites de las dos potestades eclesiástica y secular", han olvidado que todo lo relativo a la impresión y circulación de libros "es propio y privativo de la potestad temporal", la cual dispone lo que cree conveniente "haciendo en estos últimos tiempos las variaciones que las luces del siglo y las actuales necesidades de la nación han exigido." 42 Como cabe constatar, la argumentación no variaba ni en una parte ni en la otra.

Muchos obispos españoles añoraban la Inquisición. La Santa Sede no, porque no deseaba revivir un tribunal que en los años inmediatos anteriores había actuado más al servicio del rey que de la Iglesia, ${ }^{43}$ pero estaba tan preocupada como los obispos por el desarrollo de la libertad de imprenta. Más aún después del decreto de la Junta Provisional del 21 de abril de 1820, que declaraba libre la introducción de libros y estampas en el territorio nacional. ${ }^{44}$ Según muchos prelados, España se vio inundada de escritos irreligiosos e inmorales. De modo que Pío VII intervino directamente en el asunto. El 30 de agosto de 1820 envió una carta al cardenal Borbón, primado de España, instándole a vigilar estrechamente las publicaciones. El papa se pronunció en términos muy alarmantes y tal vez fue demasiado lejos en su denuncia: España corre un "gravísimo peligro", se esparcen "dogmas impíos", "la malicia y descaro de los incrédulos...se propone destruir la religión entera", decía entre otras

40 Sobre la actividad represora de la Regencia realista, vid. Jean Sarrahil, La Contre Révolution sous la Régence de Madrid (mai-octubre 1823), Ligugé (Vienne), 1930. 44)

41 Edicto del obispo de Osma, 15 de marzo de 1820 (Colección Eclesiástica Española, III, pp. 43-

42 Circular del ministerio de Gracia y Justicia, 7 de septiembre de 1820 en Juan Muñiz Miranda, Colección..., op. cit. p. 337. Las pastorales de los ordinarios sobre prohibición de libros pueden verse en la Colección Eclesiástica Española (vid. una relación en T. III, p. 41)

43 En este sentido fue demoledor el despacho de Giustiniani del 17 de marzo de 1820, reproducido por Luis Alonso Tejada, ocaso de la Inquisición..., op. cit., pp. 233-235. Vid. asimismo Emilio La Parra y María Ángeles Casado, La Inquisición en España. Agonía y abolición, Madrid, La Catarata, 2013, pp. 132-154.

44 Decreto de la Junta Provisional del 21 de abril de 1820, en Juan Muñiz Miranda, Colección..., op. cit., p. 97. 
$\operatorname{cosas.~}^{45}$ El temor a la opinión pública, a la nueva política, no podía ser más patente.

Motivo de grave inquietud para los obispos fue asimismo el decreto de la Junta Provisional del 24 de abril sobre la enseñanza de la Constitución. Obligaba a hacerlo en las escuelas de primeras letras, universidades, seminarios y conventos, e indicaba expresamente a los párrocos que los domingos y festivos debian explicarla en sus templos. El propio texto reconocía que con esta medida se pretendía reparar los "dolorosos abusos" realizados por algunos -la alusión a los clérigos, aunque implícita, es innegable- y combatir "la falsas imputaciones dirigidas contra la Constitución." 46 Como en el tiempo de la Ilustración, el poder político solicitaba de nuevo la colaboración del clero para llevar las nuevas ideas a la población, y como entonces, la respuesta fue dispar y en todo caso no se cumplieron las expectativas del poder civil. En realidad, como ha escrito Rodríguez López-Brea en relación a la diócesis de Toledo, "cada cura hizo lo que le vino en gana", y lo mismo cabe decir de los obispos: unos, los menos, instaron a sus párrocos a tomar en serio este cometido, mientras que otros se limitaron a cumplir la orden con apatía, o la tergiversaron hasta desvirtuar su sentido, o simplemente no la cumplieron. ${ }^{47}$

Un caso muy sonado de desobediencia fue el del obispo de Orihuela Simón López, quien se había distinguido en las Cortes de Cádiz como uno de los diputados "serviles" más radical y combativo. El 28 de marzo de 1820 publicó una pastoral negándose a ejecutar la orden del Gobierno sobre la explicación de la Constitución en los templos. Fue la primera muestra de rebeldia de este prelado, quien prosiguió en la misma actitud hasta ser extrañado de su diócesis por orden del Gobierno. ${ }^{48}$ Mayor entidad tuvo la reacción del arzobispo de Valencia, Fr. Veremundo Arias Teixeiro. El 31 de julio de ese año publicó una pastoral, redactada con cierta habilidad, contraria en su espíritu a la Constitución, pero a primera vista podía interpretarse como un intento de hermanar la orden sobre la explicación de la Constitución con las obligaciones pastorales de los curas ${ }^{49}$.

Arias Teixeiro no incitó a los párrocos a negarse sin más a explicar la Constitución, pero les acotó el terreno: no debian mezclarse "en materias puramente politicas, para no aventurarse a dar exposiciones siniestras y ajenas de su verdadero espíritu". En concreto, sugería que sus pláticas se circunscribieran a dos artículos constitucionales, el 6 y el 12, que consideraba los más acordes con la religión. Ahora bien, para evitar desviaciones, ofrecía una interpretación particular de ambos. Respecto al artículo 6, obviaba la obligación

45 Carta de Pío VII al cardenal primado, 30 de agosto de 1820, Colección Eclesiástica Española, I, pp. 49-55. Sobre la reacción de Borbón, vid. Carlos Rodríguez López-Brea, Don Luis de Borbón..., op. cit., pp. 299-305.

46 Real Decreto de 24 de abril de 1820, en Juan Muñiz Miranda, Colección..., op. cit., p. 100.

47 Carlos Rodríguez López-Brea, Don Luis de Borbón..., op. cit., pp. 294-295.

48 Maximiliano Barrio, La Santa Sede y los obispos..., op. cit., p. 58.; Luis Barbastro, Revolución liberal y reacción (1808-1833). Protagonismo ideológico del clero en la sociedad valenciana, Alicante, Caja de Ahorros Provincial, 1987, pp. 112-114.

49 Luis Barbastro, Revolución liberal..., op. cit., p. 94 y Manuel Revuelta, Politica religiosa de los liberales..., op. cit., p. 134. 
de los españoles de amar a la patria, y aconsejaba a los curas que se limitaran a resaltar el deber de ser justos y benéficos. ${ }^{50} \mathrm{El}$ arzobispo, pues, prescindía de la obligación civil, la principal según la Constitución (el amor a la patria), y se ceñía a un principio que bien podia tomarse como precepto religioso. Pero el arzobispo exhortó a que la explicación de la Constitución se centrara sobre todo en el artículo 12, "la base civil de la verdadera Religión en la Monarquía Española", pues "todo lo comprende este artículo fundamental en el orden civil". Este mandato constitucional, afirmó el arzobispo, afianza la religión católica en España y al mismo tiempo apoya todas las leyes de la religión y de la Iglesia; es decir, la Constitución sancionaba un orden sacralizado. Bien se podia deducir de ello que los católicos, los buenos españoles, podian rechazar cualquier precepto constitucional -y todo decreto o disposición- que no se acomodase al orden religioso. Coherente con este planteamiento, el arzobispo descendió a una cuestión concreta: a pesar de la supresión de la Inquisición, el artículo 12, bien entendido, no autorizaba la lectura y escritura de papeles anticristianos e irreligiosos, pues la libertad de imprenta no es ilimitada. Así pues -especificabatodo escrito que desacredite o calumnie al clero en general y a los eclesiásticos en particular es contrario al artículo 12, pues la táctica seguida por los impíos para trastornar y corromper la Iglesia consiste en comenzar por la persecución de los eclesiásticos. En definitiva, aunque el arzobispo de Valencia no prohibía expresamente a los párrocos que explicaran la Constitución, desvirtuaba por entero la orden de la autoridad civil e instrumentalizaba a su antojo el texto constitucional. Por lo demás, en su exhortación final dejó bien claro su auténtico propósito: los párrocos debían tratar exclusivamente de los artículos conformes a la religión, "sin necesidad de entrar jamás en discusión puramente politica que pueda distraer la atención de los oyentes del Santo Sacrificio de la Misa."51 Era una forma muy clara de decir que no enseñaran la Constitución.

Es evidente que el objetivo fundamental de la pastoral de Arias Teixeiro tenía un carácter marcadamente combativo. Constituía, ni más ni menos, un ataque al fundamento del constitucionalismo. Firme en esta dirección, el 20 de octubre, cuatro meses después de la pastoral mencionada, este prelado envió una "Representación a las Cortes" que causó auténtico revuelo, porque contenía una censura completa de la política eclesiástica del nuevo régimen, y además pretendió actuar como un llamamiento para movilizar contra él al episcopado español. También intentó comprometer al rey, al que remitió su "Representación" con una carta en la que solicitaba que "desplegara en esta ocasión todo su poder, su zelo y su piedad en favor de esta afligida Iglesia." 52

La representación a las Cortes era una encendida defensa de la inmunidad del cuerpo eclesiástico, de sus bienes y de las órdenes religiosas, y la negación

$50 \mathrm{El}$ artículo 6 disponía lo siguiente: "El amor a la patria es una de las principales obligaciones de todos los españoles y asimismo el ser justos y benéficos."

51 Pastoral del arzobispo de Valencia, 31 de julio de 1820, en Colección Eclesiástica Española, III, pp. 123-147. Vid. Manuel Revuelta, Politica religiosa de los liberales..., op. cit., p. 134. Una semblanza de Arias Teixeiro en Luis Barbastro, Revolución liberal..., op. cit., pp. 84-99.

52 "Carta del Señor Arzobispo de Valencia a S. M., remitiendo la representación que dirigía a las Cortes”, 27 de octubre de 1820 (Colección Eclesiástica Española, IV, pp. 5-7) 
tajante de facultades al poder civil para intervenir en los asuntos de la Iglesia. ${ }^{53}$ La importancia de este escrito no radica en su argumentación, idéntica a la empleada en sus notas por el nuncio, sino en su repercusión entre el episcopado. Buena parte de los ordinarios expresó por escrito y con calor su conformidad con el texto del de Valencia, y varios afirmaron haber enviado escritos similares a las Cortes sin recibir respuesta, o estar dispuestos a hacerlo. Todos entendieron que había llegado el momento de formar un frente común, como indicó expresamente Pedro Inguanzo, obispo de Zamora, en su carta de adhesión al arzobispo valentino: ante la avalancha de medidas contra la Iglesia, "era menester que todos le imitásemos, y aquí quisiera yo una dirección"; hay que "uniformar nuestras medidas." 54

No consiguió Arias Teixeiro su propósito de unificar al episcopado español. $\mathrm{Su}$ representación fue declarada subversiva por el jefe político de Valencia (así consta en un aviso al público difundido el 15 de noviembre en el Diario de la Ciudad de Valencia), el arzobispo fue detenido y recluido en el Colegio de las Escuelas Pías de esa ciudad. El prelado escribió tres veces a Fernando VII solicitando su intervención, pero el monarca nada hizo. El 24 de noviembre Arias Teixeiro se vio obligado a embarcar en dirección a Francia, donde permanecería hasta 1823.55

Se podría decir que el testigo del arzobispo de Valencia lo tomó el de Zaragoza, Manuel Martínez Jiménez, ya distinguido, como otros destacados realistas de este tiempo, en la época de las Cortes de Cádiz por su oposición a la política liberal, hasta el punto de que en 1813 le costó el exilio a Portugal. ${ }^{56}$ En unión de sus sufragáneos, los ordinarios de Barbastro, Jaca, Tarazona, Albarracín y Teruel (solo faltó el de Huesca) firmó dos representaciones al rey y a las Cortes, fechadas el 4 de noviembre y el 22 de diciembre de 1820.57 De nuevo estamos ante una crítica en toda regla a la obra de las autoridades constitucionales en materia eclesiástica, la cual es examinada temáticamente con cierto detalle en la segunda representación. Ambos textos, prolijos en citas bíblicas, de concilios, papas y notorios escritores santos de la Iglesia, trataban de demostrar que la finalidad última de las reformas eclesiásticas era la destrucción de la religión. Vivimos en tiempos de incredulidad, se dice en la primera, "la impiedad ...hace los últimos esfuerzos para desterrar (si fuese posible) del mundo

53 Representación a las Cortes del arzobispo de Valencia, 20 de octubre de 1820 (Colección Eclesiástica Española, IV, pp. 10-77)

54 Carta del obispo de Zamora al arzobispo de Valencia (Colección Eclesiástica Española, IV, pp. 87-89). Otros 23 obispos escribieron en un tono parecido al de Valencia (pp. 77-106)

55 Las representaciones de Arias Teixero al rey, datadas los dias 11, 14 y 18 de noviembre, en Archivo General de Palacio (Madrid), Papeles Reservados de Fernando VII, T. 22, ff. 18-25. No fue la de Arias Texeiro la única petición desesperada de uno de sus más fieles desatendida por Fernando VII; lo mismo le sucedió al capitán general de Valencia Francisco Javier Elio. Vid. Encarna y Carmen Garcia Monerris, La nación secuestrada. Francisco Javier Elio. Correspondencia y Manifiesto, Valencia, PUV, 2008.

56 Breve nota biográfica de este prelado en Colección Eclesiástica Española, II, pp. 184-185.

57 Ambas representaciones están publicadas en Colección Eclesiástica Española, II, pp. 184292. El texto original manuscrito de las dos, con las firmas de sus autores, en el T. 22 de Archivo General de Palacio (Madrid), Papeles Reservados de Fernando VII. Los recopiladores de la Colección Eclesiástica datan la primera el 4 de octubre, pero en el manuscrito figura 4 de noviembre, fecha esta última que considero la exacta. 
toda la religión verdadera...", y por eso "se clama tanto por la reforma de las costumbres y de los abusos introducidos en la disciplina." Como el resto de la jerarquía eclesiástica, los obispos de Aragón negaron facultad al poder civil para intervenir en la Iglesia, cuya disciplina solo se podía alterar previo permiso del papa o mediante un concilio, nacional o provincial. De ahí que instaran al rey, "como depositario del poder ejecutivo", a suspender todas las medidas eclesiásticas decretadas por las Cortes, es decir, le pedían que ejerciera su derecho al veto.

No acababan de asumir los prelados de Aragón la división de poderes (su concepto de la monarquía seguía anclado en el Antiguo Régimen), pero a diferencia de otros textos de la misma naturaleza, reconocían expresamente en su primera representación la soberanía de la nación, si bien recalcando que estaba circunscrita a lo temporal. Así pues, mantuvieron un concepto sacralizado de la politica y antepusieron la autoridad de la Iglesia a la del poder civil: "la autoridad de la Iglesia es privativa e independiente, y lejos de ser reformada es preciso que sea obedecida de las demás." De acuerdo con este principio, que en rigor era un llamamiento a mantener el statu quo, descalificaron todas las reformas, por ser contrarias al dogma o a las costumbres de la Iglesia, y defendieron la inmunidad del clero, pues en razón de su ministerio sagrado, los sacerdotes -se dice en la segunda representación- están por encima de los demás hombres, "y así la razón misma nos conduce naturalmente a colocarlos en una esfera superior a la de la tierra y en una clase superior a la de los hombres." Por este motivo, concluyeron, en todas las culturas, incluso en las paganas, se concede inmunidad al sacerdote.

A pesar de su tono inmovilista, las representaciones de los prelados aragoneses asumian la posibilidad de realizar algunas reformas, aunque no especificaron ninguna, si bien se cuidaron en precisar que solo podrian efectuarlas el papa o los obispos reunidos en concilio.

La idea de convocar un concilio nacional para acometer la reforma general eclesiástica en España había sido expuesta con detalle y extensión por la Comisión Eclesiástica de las Cortes de Cádiz. ${ }^{58}$ Entonces todo quedó en el papel. Ahora tampoco prosperará, fundamentalmente porque no interesaba a la Santa Sede. Sobre el concilio trató la Congregación especial formada por el papa, la cual rechazó tajantemente la posibilidad de su convocatoria. En opinión del cardenal Pacca, uno de sus integrantes, una reunión de esa naturaleza, deseada desde siempre por jansenistas y filósofos, sería peligrosa "en estos tiempos de general efervescencia", de manera que "sobre este punto desde Roma se debe actuar sin miramientos." La Congregación encargó al nuncio en España que se empleara a fondo para impedir un concilio, fuera nacional o provincial, pues de él podría nacer un cisma. 59

58 El plan del concilio de la Comisión Eclesiástica, fechado el 15 de agosto de 1811, titulado: "Memoria de algunos puntos de disciplina externa que las Cortes Generales y Extraordinarias de España presentan al examen del Concilio Nacional" está reproducido casi íntegro en Emilio La Parra, El primer liberalismo y la iglesia. Las cortes de Cádiz, Alicante, Instituto de Estudios Juan Gil-Albert, 1985, pp. 273-286.

59 Roberto Regoli, “La Congregación especial...”, op. cit. p. 160. 
La posibilidad de un cisma en la Iglesia española fue otra inquietud constante de la Santa Sede durante el Trienio Liberal. La alimentaban, por una parte, las alusiones del episcopado, como las que se acaban de mencionar, a la celebración de un concilio como vía para atajar la política regalista del régimen constitucional; por otra, el nombramiento por el gobierno de gobernadores eclesiásticos en las diócesis cuyos ordinarios se vieron obligados a abandonar por razones políticas, que no fueron pocas. Como dijo el cardenal Pacca, los tiempos eran "de general efervescencia". Se mantenía en el recuerdo la división de la Iglesia francesa durante la Revolución, y las ideas episcopalistas no habían desaparecido de la mente de muchos eclesiásticos, incluso de obispos opuestos al liberalismo. Un concilio nacional, o provincial, podría ser un instrumento para avivar estas ideas, o al menos para rebajar la autoridad del papa sobre la Iglesia española hasta derivar en conciliarismo, y lo que ahora interesaba a la Santa Sede era fidelizar de la forma más estrecha posible al episcopado católico. 60 Por este motivo resultaba prioritario, asimismo, evitar que ciertos canónigos se hicieran cargo del gobierno de las sedes vacantes, y más aún que accedieran al episcopado individuos claramente tildados de jansenistas, cuales fueron los casos de José Espiga y Muñoz Torrero, propuestos por el gobierno liberal para ocupar respectivamente las diócesis de Sevilla y Guadix. Estas cuestiones ocuparon intensamente a la Santa Sede y constituyeron uno de los máximos cuidados del nuncio Giustiniani. ${ }^{61}$

\section{CONCLUSIÓN}

Durante el Trienio Liberal fue permanente la conflictividad entre las autoridades civiles y el episcopado español. ${ }^{62}$ En un primer momento el alto clero se movió entre la aceptación formal del nuevo sistema y la crítica en pastorales y sermones de forma no excesivamente llamativa de sus principios fundamentales, en especial la soberanía nacional. Sin embargo, casi al mismo tiempo un buen número de obispos manifestó su negativa a aceptar dos de las medidas iniciales más importantes adoptadas por la nueva autoridad civil: la abolición de la Inquisición y la declaración de la libertad de imprenta. A medida que se fue desarrollando la politica liberal, la conflictividad fue en aumento. Por una parte, se configuró un bloque político contrario al constitucionalismo, en el que fue un agente importante la jerarquía eclesiástica, siempre en contacto con Roma a través del nuncio Giustiniani; por otra, quedó patente la imposibilidad de avanzar en el ideal de Iglesia de los primeros liberales. La oposición eclesiástica al sistema constitucional alcanzó su culmen en 1822: el clero participó activamente en conspiraciones contra el régimen, y se comprometió directa e intensamente en la organización de Juntas y guerrillas para derribarlo por la fuerza, sin cesar en la condena verbal y por escrito de la actuación del poder civil. ${ }^{63}$ La ruptura

60 Sobre los esfuerzos de la Santa Sede para ganarse la fidelidad de los obispos españoles vid. Antoni Artola Renedo, De Madrid a Roma. La fidelidad del episcopado en España (1760-1833), Gijón, Trea, 2013, especialmente pp. 321-344.

${ }^{61}$ La crisis en el gobierno de las diócesis en Manuel Revuelta, Política religiosa de los liberales... op. cit, pp. 340-350.

62 Manuel Teruel, Obispos liberales... op. cit., p. 233.

63 Uno de los enfrentamientos más aparatosos, aparte de los apuntados en páginas anteriores, fue el del obispo de Ceuta, Fr. Rafael de Vélez, luego elevado a la archidiócesis de Santiago de 
completa tuvo lugar en 1823: el clero anticonstitucional no ocultó su empeño por exterminar definitivamente y de raíz el liberalismo, hasta el punto de que algunos eclesiásticos actuaron desde el poder ejecutivo como agentes represivos de los más significados (el obispo Mariano de Cavia fue miembro de la Regencia realista de 1823, la cual nombró ministro al canónigo Víctor Damián Sáez).

Frente a la oposición eclesiástica, el poder civil reaccionó con medidas que poco a poco fueron perdiendo el carácter genuinamente reformista y adquirieron un tono represivo. A partir de la segunda legislatura del Trienio, iniciada en febrero de 1821, las Cortes se limitaron a clarificar sus decisiones del año anterior (sobre todo acerca de la supresión de beneficios, las secularizaciones de regulares y la pérdida de la inmunidad eclesiástica) o a controlar al clero. En rigor, ya solo tuvieron carácter reformista la reducción del diezmo a la mitad y la prohibición del pago de dispensas a Roma. Sin embargo, las Cortes no se mantuvieron inactivas en relación con el clero. Negaron la posibilidad de ser diputados a Cortes a los obispos y al resto del alto clero "que para el ejercicio de sus funciones necesiten la aprobación o el nombramiento del gobierno"64; ordenaron el extrañamiento del reino y la ocupación de sus temporalidades de los obispos "que se aparten de sus deberes"65; adoptaron medidas para castigar a los eclesiásticos que actuaran contra el sistema politico66; se suprimieron los conventos y monasterios situados en despoblado o en pueblos con menos de 450 vecinos, salvo el de San Lorenzo del Escorial. ${ }^{67}$

Llegados a octubre de 1823, a punto de ser derrocado el sistema constitucional por la fuerza de las armas, gracias a la invasión de los Cien Mil Hijos de San Luis, se puede decir que se habían roto los lazos de unión entre el sistema constitucional y la jerarquía eclesiástica española y romana. Prueba de ello fue la dura represión del clero liberal a partir de ese momento y el abandono por el régimen de Fernando VII de todo proyecto de reforma eclesiástica. Por otra parte, como consecuencia de la participación del clero en las partidas armadas realistas, se recrudeció el ambiente anticlerical en los medios liberales más exaltados, llegando incluso al asesinato de clérigos, especialmente en aquellos territorios, como el norte de España, donde el realismo tuvo mayor presencia y el clero participó de forma más activa en las partidas armadas realistas, esto es, alli donde el conflicto político fue más exacerbado.

Los gruesos catorce volúmenes de que consta la Colección Eclesiástica Española, elocuente recopilación de la reacción frente al régimen constitucional

Compostela. Vid. Josep Escrig Rosa, "La política del siglo no es para la casa de Dios. Fray Rafael de Vélez en tiempos de liberalismo y revolución (1820-1823)", en Ivana Frasquet y E. García Monerris, Tiempo de política, tiempo de Constitución. La monarquía hispánica entre la revolución y la reacción (1780-1849), Granada, Comares, 2018, pp. 239-262.

64 Decreto de Cortes del 26 de junio de 1821, en Colección de los Decretos y órdenes generales expedidos por las Cortes, Madrid, Imprenta Nacional, 1821, T. VII, p. 196.

65 Orden del 6 de mayo de 1822, Colección de los Decretos y órdenes generales expedidos por las Cortes, Madrid, Imprenta Nacional, 1822, T. IX, p. 120.

66 Orden del 30 de abril de 1821, Colección de los Decretos y órdenes..., op. cit., T. VII, pp. 6163, reiterada con algunas variantes el 29 de junio de 1822 (Ibíd. T. IX, p. 556) y el 1 de noviembre de este último año (ibid. T. X, p. 16)

67 Decreto del 15 de noviembre de 1822, Colección de los Decretos y órdenes..., op. cit, T. X, p. 31. 
por parte del episcopado español y de la Santa Sede, muestran que la jerarquía eclesiástica, incluido el Papa Pío VII, exageró no poco sobre las intenciones de la politica reformista liberal. Algunas pastorales, singularmente las del capuchino Vélez, "muestran -ha escrito Manuel Teruel- no solo un enfoque formalmente acristiano, o incluso anticristiano, de esas situaciones de conflicto, sino su utilización, consciente o inconscientemente, como recurso eficaz para llamar la atención de los fieles sobre una amenaza exterior que a la larga los distraía de los verdaderos problemas eclesiales internos." 68 Creo que así fue, porque la materia de conflicto no fue la religión, ni la Iglesia como institución, sino el poder. La jerarquía eclesiástica puso todo su empeño en atajar una reforma en profundidad de las estructuras del Antiguo Régimen, porque ponía en peligro su influencia sobre las decisiones politicas, su potencial económico, su dominio sobre la opinión pública y el estatus privilegiado del cuerpo eclesiástico. Los liberales intentaron construir un nuevo Estado, en el que tuviera primacía la nación, a través de sus representantes electos, reunidos en Cortes. Los liberales, fueran moderados o exaltados, no se plantearon eliminar el carácter católico de la monarquía española, ni la confesionalidad del Estado. La cultura católica siguió siendo hegemónica en España. El liberalismo español, en suma, tuvo muy en cuenta la importancia de la religión en la construcción del Estado-nación, pues "la herencia religiosa representaba a menudo un sustrato identitario enormemente importante para la consagración de la lealtad nacional.”69

Fecha de envío / Submission date: 12/02/2020

Fecha de aceptación / Acceptance date: 15/04/2020

68 Manuel Teruel, Obispos liberales... op. cit., p. 222.

69 Jesús Millán y Ma Cruz Romeo, "Presentación”, a Heinz-Gerhard Haupt y Dieter Langewiesche, Nación y religión en Europa. Sociedad multiconfesionales en los siglos XIX y XX, Zaragoza, Institución Fernando El Católico, 2010, p, 15. 